\section{PD23-03 \\ PROSPECTIVE RANDOMIZED STUDY COMPARING MONOPOLAR WITH BIPOLAR TRANSURETHRAL RESECTION OF PROSTATE ON A LARGE COHORT OF PATIENTS WITH BENIGN PROSTATIC OBSTRUCTION: LONG TERM OUTCOMES}

Giovanni Palleschi*, Antonio Luigi Pastore, Yazan Al Salhi, Andrea Fuschi, Gennaro Velotti, Antonino Leto, Antonio Carbone, Latina, Italy

INTRODUCTION AND OBJECTIVES: Monopolar transurethra resection of the prostate (TURP) is the gold standard surgical treatment for bothersome moderate to severe lower urinary tract symptoms (LUTS) secondary to benign prostate obstruction with enlarged prostates. The aim of the study is to compare monopolar vs. bipolar TURP focusing on operative and functional outcomes with a long term follow-up.

METHODS: From January 2007 to July 2013 a total of 379 patients were randomized and prospectively scheduled to undergo bipolar (202) or monopolar (177) TURP. International prostate symptom score (IPSS), IPSS-Quality of life (QoL), post-void residual and maximum flow rate were assessed preoperatively and postoperatively at 3,12, 24 and 36 months. Operative time, length of catheterization and length of hospitalization were all recorded. Rates of urethral strictures and bladder neck contractures were also reported.

RESULTS: Perioperative results showed no statistical significance between the two groups in terms of catheterization days, postvoid residual, IPSS, IPSS-QoL score, blood transfusion and TUR syndrome. The operative time was proved to be statistically significant in the monopolar group while the hospitalization days was found statistically significant in the bipolar group. The 3,12, 24 and 36 months follow up showed significant and equal improvements in LUTS related to BPO in the 2 treatment groups.

CONCLUSIONS: Monopolar and bipolar TURP are safe and effective techniques for BPH. The 2 significant differences between them were operative time in favour of the monopolar group and hospitalization days in favour of the bipolar group. Bipolar TURP has the principle advantage in preventing TUR syndrome that was reported in 2 monopolar TURP patients.

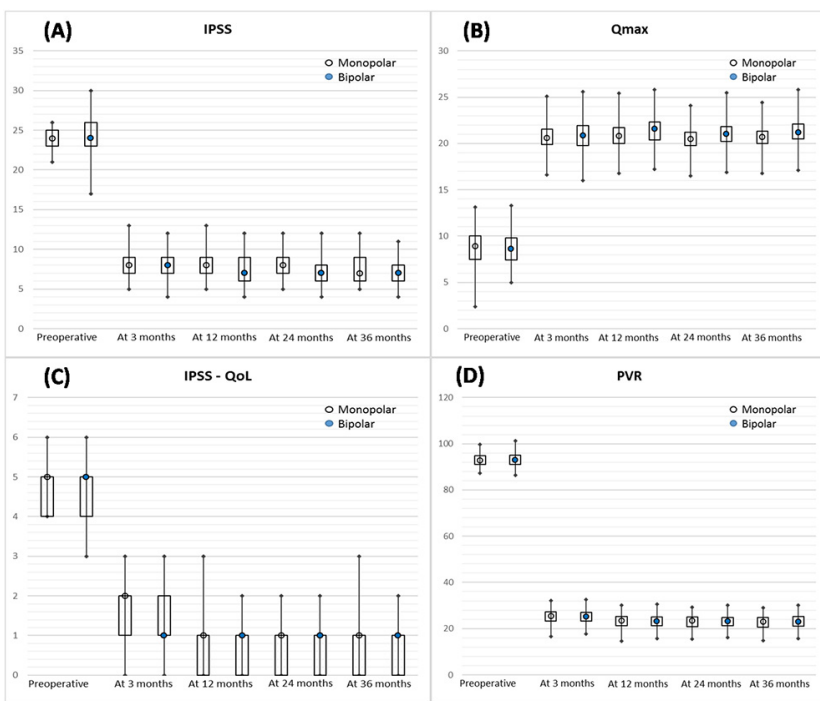

Source of Funding: None
PD23-04

THULIUM LASER ENUCLEATION (THULEP) VERSUS TRANSURETHRAL RESECTION OF THE PROSTATE IN SALINE (TURIS): A RANDOMIZED PROSPECTIVE TRIAL TO COMPARE COSTS PER PROCEDURE

Giorgio Bozzini*, Castellanza, Italy; Stefano Casellato, Serena Maruccia, Monza, Italy; giovanni saredi, varese, Italy; paolo parma, mantova, Italy; Gianluigi Taverna, Castellanza, Italy

INTRODUCTION AND OBJECTIVES: To compare the costs per procedure between thulium laser transurethral enucleation of the prostate (ThuLEP) and transurethral bipolar resection of the prostate (TURIS) for treating benign prostatic hyperplasia (BPH) in a prospective randomized trial.

METHODS: The study randomized 208 consecutive patients with BPH to ThuLEP $(n=102)$ or TURIS $(n=106)$. For all patients were evaluated preoperatively with regards to blood loss, catheterization time, irrigation volume, hospital stay and operative time. At 3 months after surgery they were also evaluated by International Prostate Symptom Score (IPSS), maximum flow rate (Qmax), and postvoid residual urine volume (PVR) to see if a cost reduction could be correlated with a worst outcome.

RESULTS: The patients in each study arm each showed no significant difference in preoperative parameters. Compared with TURIS, ThuLEP had same operative time $(53.69 \pm 31.44$ vs $61.66 \pm 18.70$ minutes, $P=.123$ ) but resulted in less hemoglobin decrease $(0.45$ vs $2.83 \mathrm{~g} / \mathrm{dL}, \mathrm{P}=.005)$. ThuLEP also needed less catheterization time (1.3 vs 4.8 days, $P=.011)$, irrigation volume (29.4 vs $69.2 \mathrm{~L}, \mathrm{P}=.002)$, and hospital stay (1.7 vs 5.2 days, $\mathrm{P}=.016$ ). Average cost for a ThuLEP was 1181 euros while was 1761,16 for a TURIS $(p<.005)$. During the 3 months of follow-up, the procedures did not demonstrate a significant difference in Qmax, IPSS, PVR, and QOLS.

CONCLUSIONS: ThuLEP and TURIS both relieve lower urinary tract symptoms equally, with high efficacy and safety. ThuLEP was statistically superior to TURIS as a cheaper procedure. However, procedures did not differ significantly in Qmax, IPSS, PVR, and QOLS through 3 months of follow-up.

Source of Funding: none

\section{PD23-05 \\ INFERIOR TISSUE ABLATION AFTER 120W GREENLIGHT LASER VAPORIZATION DOES NOT TRANSLATE INTO INFERIOR CLINICAL OUTCOME COMPARED CONVENTIONAL TURP: 3-YEAR RESULTS OF A PROSPECTIVE 3D ULTRASOUND VOLUMETRY STUDY}

Benedikt Kranzbühler*, Oliver Gross, Christian D. Fankhauser, Marian S. Wettstein, Nico C. Grossmann, Etienne X. Keller, Daniel Eberli, Tullio Sulser, Cédric Poyet, Thomas Hermanns, Zurich, Switzerland

INTRODUCTION AND OBJECTIVES: Functional short-term outcome following $120 \mathrm{~W}$ greenlight laser vaporization (LV) has been shown to be comparable to conventional transurethral resection of the prostate (TURP). However, mid-term results following $80 \mathrm{~W}$ greenlight LV revealed that high retreatment rates are common after the procedure most likely due to insufficient tissue ablation. Short-term outcome of our 3D ultrasound volumetry study revealed a significantly lower volume reduction one year after $120 \mathrm{~W}$ LV compared to TURP. Additional followup was now performed to investigate further changes in volume reduction and associated clinical outcome 3 years after LV and TURP. METHODS: A total of 174 patients (120W LV; $n=98,56 \%$ vs. TURP; $n=76,44 \%$ ) were included in this prospective study and were followed for 3 years. Transrectal 3D ultrasound and planimetric volumetry of the prostate was performed preoperatively, after catheter removal, 6W, 6M, 12M and 3Y. Clinical outcome parameters (PSA, 